\title{
Economic crisis and malnutrition: socioeconomic determinants of anthropometric status of preschool children and their mothers in an African urban area
}

\author{
F Delpeuch ${ }^{1, *}$, P Traissac ${ }^{1}$, Y Martin-Prével ${ }^{1}, J P$ Massamba ${ }^{2}$ and B Maire ${ }^{1}$ \\ ${ }^{1} I R D$, Institut de Recherche pour le Développement (formerly Orstom), Nutrition Unit, WHO Collaborating Centre \\ for Nutrition, BP 5045, 34032 Montpellier, France: ${ }^{2}$ DGRST, Brazzaville, BP2499 Congo
}

Submitted 11 February 1999: Accepted 20 July 1999

\begin{abstract}
Objective: To assess the relative importance of socioeconomic and maternal/prenatal determinants of the nutritional situation of children $<6$ years old in an urban African area after several years of economic crisis.

Design: Cross-sectional cluster sample survey.

Setting: Brazzaville, capital city of the Congo.

Subjects: Information on socioeconomic characteristics was gathered from a random sample of 1368 households by house visits and anthropometric measurements were performed using standardized procedures on preschool children $(n=2373)$ and their mothers $(n=1512)$.

Results: The influence of socioeconomic factors on the nutritional status of children, taking into account adjustment variables such as mother's age and child's age and sex was assessed. For stunting, as well as for the mean height-for-age index among children, the main determinants were economic level of the household $(P=0.048$ and $P=0.004$, respectively), schooling of the mother $\left(P=0.004\right.$ and $\left.P<10^{-3}\right)$ and living in the peripheral district $\left(P=0.005\right.$ and $\left.P<10^{-3}\right)$. The influence of socioeconomic determinants on weight-for-age and wasting was less straightforward. When adjusting, in addition, for maternal and prenatal factors (mother's height and body mass index (BMI) and birth weight), most of the effects of the socioeconomic determinants on the nutritional status of children persisted somewhat, but the effect of the economic level on the stunting became not significant $(P=0.11)$. The mean BMI of mothers appeared to be related to the economic level of the household $\left(P<10^{-4}\right)$, to the marital status $(P=0.01)$ and to the occupation of the mother $\left(P<10^{-4}\right)$.

Conclusions: Among the socioeconomic determinants of malnutrition in children, some, such as economic level of the household or schooling of the mother, seem to act mainly through prenatal factors, whereas others, mainly dwelling district characteristics, seem to influence more directly the children's nutritional status.
\end{abstract}

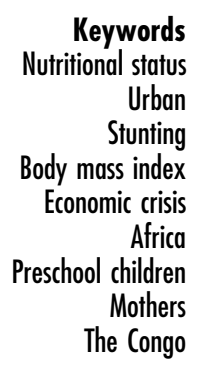

The present work aims at understanding the socioeconomic determinants of the nutritional situation, in an urban area in central Africa, after several years of economic crisis. In the early 1980s, the second rise in oil prices and the recession in industrialized countries had dire consequences on the economies of most sub-Saharan countries. Various stabilization and structural adjustment programmes were implemented in these countries. Together with the influence of the economic crisis itself, these programmes, often including drastic reduction in health and educational budgets, can have, in the short term, negative effects on the nutritional situation, especially among the poorest. This was shown for example in West Africa in the Ivory Coast ${ }^{1}$.

The Congo, which enjoyed a fair economic growth up to the mid-1980s, mainly due to oil revenues, was forced to implement a first structural adjustment plan in 1986. The consequences of the economic crisis and adjustment measures on employment and household income, especially in urban areas, had negative effects on the availability and use of food products. The measures also had negative effects on budget allocation in priority social sectors. As a result, the families bore an increasing share of medical and educational costs ${ }^{2}$.

A nutritional survey, carried out in 1986 in Brazzaville, capital city of the Congo, on a representative sample of children $<6$ years old and their mothers provided basic data immediately before the implementation of the first adjustment plan ${ }^{3}$. Another survey, performed in 1991 by the same team using the same methodology, allowed an assessment of the evolution of anthropometric status between 1986 and $1991^{4}$. There were contrasting results: 
on one hand, the prevalence of overweight mothers increased and the overall height of preschool children rose (except for children in the poorest third of the population). On the other hand, an increase in the prevalence of low birth weights and of wasting in children less than 2 years old, together with an increase in the rate of thinness among young mothers $(<30$ years old) indicated a worsening nutritional situation. Overall, this indicated a negative impact of the economic crisis and adjustment policies on the nutritional situation of the population, especially among the poor in urban areas.

Beyond the changes in the nutritional situation, the objective of the present analysis was to assess the relative importance of socioeconomic and other risk factors of malnutrition in an urban context experiencing a socioeconomic upheaval. Data from the 1991 survey were relevant for such a purpose as they reflected the situation after several years of economic crisis but before the major internal conflicts which have plagued the Congo (especially the main urban area of Brazzaville) since the mid-1990s.

\section{Methods}

\section{Sampling}

The study zone is a large urban transect running from the old city centre and commercial area (district of Poto-Poto) to the urbanization front (district of Mikalou), through the intermediate district of Moungali/Ouenzé. A sample of the households living in the study zone and having at least one child aged $<6$ years was randomly selected. The sampling base was a list of blocks, sorted in clusters of approximately identical size, from the most recent population census ${ }^{5}$. All households living in the randomly selected blocks were included in the study. The number of clusters was chosen to provide approximately 2400 children aged $<6$ years (i.e. a minimum of 100 children per quarterly age group), and the number of mothers was determined by the number of children.

\section{Data collection}

The survey was performed by house visits. In a first step, all the eligible households living in a selected block were identified and advised of the objectives of the study. On the following day, the actual collection of data took place. Then, a third phase was carried out to recover the subjects missed during the preceding step.

Socioeconomic information was gathered at the household level. Information on housing characteristics (type of floor, walls and roof), access to water and electricity, as well as possessions and goods (appliances, vehicles, etc.), was used to assess the economic status. A number of other characteristics of the household were collected such as dwelling district (as a proxy to assess the general environmental conditions such as sanitation, sewage, roads, etc.), date of settlement in Brazzaville and in the present home, household size, and information on the head of household and on the mother (age, education, marital status, occupation). Other variables were also taken into account: family ties between mother, child and the head of the household and which person took care of the child.

Anthropometric measurements were performed according to standardized procedures ${ }^{6}$ to ensure accuracy and reproducibility. Weights of children under $16 \mathrm{~kg}$ were measured on baby scales (accuracy $\pm 20 \mathrm{~g}$ ). Calibrated electronic scales were used for children weighing more than $16 \mathrm{~kg}$ and for the mothers (accuracy $\pm 200 \mathrm{~g}$ ). For children aged $<24$ months, recumbent length was measured using horizontal boards (accuracy $\pm 1 \mathrm{~mm}$ ). The height of older children and mothers was measured (also to the nearest millimetre) with vertical boards. Special attention was paid to determine the age of children, using official documents whenever possible. Children for whom age was imprecisely determined were excluded from the analyses. Birth weights of children were also checked from documents and taken into account in the analyses only when verified.

\section{Nutritional indices}

According to $\mathrm{WHO}$ recommendations, children's weightfor-height and height-for-age indices were calculated with standard methodology and are presented as deviations in z-scores (or standard deviations) from the $\mathrm{CDC} / \mathrm{WHO}$ reference population mean value for the age and sex. Wasting and stunting are respectively defined as a weightfor-age and height-for-age of less than -2 z-score. Nevertheless, in this population the prevalence of wasting was fairly low whereas the rate of children having a weight-for-height index below - 1 z-score (25\%) exceeded that of the reference population (16\%). Thus, a cut-off point of $-1 \mathrm{z}$-score was used to assess the determinants of low weight-for-height. Low birth weight was defined as $<2500$ g.

Body mass index (weight $/$ height $^{2}$ ) was used to assess the nutritional status of non-pregnant mothers. Thinness was defined as a BMI $<18.5 \mathrm{~kg} \mathrm{~m}^{-2}$ and a BMI $\geqslant 25 \mathrm{~kg} \mathrm{~m}^{-2}$ defined overweight (including obesity) ${ }^{6}$.

\section{Data management and statistical analysis}

Epi-Info software ${ }^{7}$ was used for data entry and the computation of anthropometric indices. Data management and statistical analyses were performed using the SAS system ${ }^{8}$, release 6.09 for Unix.

Economic data (housing characteristics, access to water and electricity, goods and possessions) were summarized in a single economic scale; the first principal component of the correspondence analysis performed on the matrix of binary variables coding the economic variables. The scale was then divided into terciles, defining increasing levels of wealth?

A multivariate approach was used to assess the 
influence of socioeconomic characteristics on the nutritional status of children and mothers. A general linear model ${ }^{10}$ was used for continuous nutritional indices (height-for-age and weight-for-height expressed in $\mathrm{z}$ scores for children, BMI in $\mathrm{kg} \mathrm{m}^{-2}$ for mothers) and, in parallel, a generalized linear model (logistic regression ${ }^{11}$ ) was used for discrete indices (prevalence of stunting and of low weight-for-height indices in children, prevalence of thinness and of overweight in mothers). In these models the response variable was the nutritional index and all the socioeconomic variables were included as explanatory variables. Other explanatory variables were also entered for adjustment purpose. For the mothers, the only adjustment variable was age. For the children two types of models were used: model I was adjusted for the mother's age and the child's age and sex. In addition, model II was adjusted for the mother's height and BMI and for the child's birth weight. These variables were added to monitor any possible genetic and prenatal influences, including the nutritional and health history of the mother, and to assess the magnitude of their effect compared to that of the socioeconomic characteristics and dwelling district.

Subjects with missing data for at least one of the explanatory or adjustment variables were de facto excluded from this multivariate analysis. Obviously, this led to the exclusion of numerous subjects. It was checked whether the excluded subjects differed from those with no missing data: none of the verifications performed made it possible to refute the hypothesis of a random pattern in the missing data and hence of the absence of a systematic bias.

\section{Results}

\section{General features of the sample}

A total of 1368 households were surveyed in March-April 1991. There were 2373 preschool children of known age and 1512 mothers (i.e. 1.4 children per mother).

Table 1 displays the global features for the variables used in the analyses. The households were generally of moderate size and had been settled in Brazzaville for a long time (20 years or more for almost two-thirds). Respectively, $63.9 \%$ and $66.4 \%$ of the heads of households and of the mothers had attended secondary school. This rather high level of education would be unusual in West African countries, for example, but is a legacy of preeconomic crisis years when the Congo was one of the most prosperous countries of its region. Among the heads of households the percentage without professional occupation was fairly high (29\%). The most frequent job of the mothers was informal (street seller, 15.9\%) but $66.4 \%$ had no occupation. Although it is not detailed here, most of the socioeconomic characteristics were sharply contrasted between the three districts, especially between the anciently urbanized centre and the peripheral district (mainly recent settlers). The average age of the mothers was 28.8 years $(\mathrm{SD}=0.3)$ and $10.1 \%$ of them were less than 20 years old. Among the children there were $50.1 \%$ boys and $49.9 \%$ girls. Most of them had direct family ties with the head of household.

\section{Nutritional situation}

The nutritional status of the children and mothers has already been detailed ${ }^{4}$. Among the children $(n=2334)$, the main figures were as follow: the overall prevalence of wasting was $4.2 \%$ (a prevalence of a weight-for-height of less than $-1 \mathrm{z}$-score was $25.2 \%$ ) with an average weightfor-height index of -0.39 z-score $(S E M=0.02)$. As expected, the wasting was more pronounced in the youngest categories (especially 12-23 months). The overall prevalence of stunting was $11.0 \%$ with an average height-for-age index of -0.56 z-score (SEM=0.03). According to the age, the usual peak of prevalence in the 18-23 months category was not very marked (15.6\%). Among the mothers $(n=1350)$, the percentage of thinness was $10.5 \%$, whereas $28.8 \%$ were overweight. The average BMI was $23.1 \mathrm{~kg} \mathrm{~m}^{-2}$ (SEM=0.1). These figures, however, were very dependent on age: the younger the mothers, the higher the percentage of thinness, and inversely the lower the percentage of overweight.

\section{Determinants of nutritional status}

Tables 2 and 3 display the results of the general linear models for the continuous weight-for-height index and of the logistic regressions for children with a low weightfor-height index $(<-1 \mathrm{z}$-score). The mean weight-forheight index decreases when there is more than one child aged $<6$ years in the household (Table 2 , model I). No other demographic, social, economic or dwelling district variable seems to affect this index. However, the prevalence of children with a low weight-for-height index increases strongly when the mother is not salaried, the odds ratios being greater than 2 for all other categories of occupation (Table 3, model I); but the effect of having more than one child aged $<6$ years is then not significant at the 0.05 level. Adjusting for maternal and prenatal factors does not modify these conclusions (Tables 2 and 3 , model II).

Tables 4 and 5 present regression models results for the continuous height-for-age index and for stunting. Three variables have independent effects (i.e. adjusted for each other): mean height-for-age increases from the peripheral area towards the city centre, when the level of schooling of the mother rises and when the economic level of the household goes up from low to medium or high (Table 4, model I). These variables are also linked to stunting: the odds ratio is significantly higher when the economic level of the household is low, when the mother did not attend school or only completed primary education and when the household lives in the peripheral area (Table 5, model I). 
Table 1 General features of the variables used in the models

\begin{tabular}{|c|c|c|c|c|c|}
\hline $\begin{array}{l}\text { Variables at the household level } \\
(n=1368)\end{array}$ & $\%$ & $\begin{array}{l}\text { Additional variables for mothers } \\
\qquad(n=1512)\end{array}$ & $\%$ & $\begin{array}{l}\text { Additional variables for children } \\
\qquad(n=2373)\end{array}$ & $\%$ \\
\hline Dwelling district & & Matrimonial status & & Ties with the head of household & \\
\hline Centre & 20.8 & Married & 66.2 & Son/daughter & 73.5 \\
\hline Intermediate & 50.4 & Single & 33.8 & Grandson/granddaughter & 18.9 \\
\hline \multirow[t]{2}{*}{ Peripheral } & 28.7 & & & Other & 7.6 \\
\hline & & Head of household & & & \\
\hline Number of persons in the household & & Yes & 11.6 & Person caring for & \\
\hline $1-4$ & 37.9 & No & 88.4 & Mother & 91.7 \\
\hline $5-9$ & 48.2 & & & Other & 8.3 \\
\hline $10-14$ & 11.3 & Wife of head of household & & & \\
\hline $15+$ & 2.6 & $\begin{array}{l}\text { Yes } \\
\text { No }\end{array}$ & $\begin{array}{l}66.7 \\
33.3\end{array}$ & & \\
\hline \multicolumn{6}{|l|}{ Number of preschool children } \\
\hline 1 & 48.2 & Occupation & & & \\
\hline 2 & 36.7 & Salaried & 9.3 & & \\
\hline \multirow[t]{2}{*}{$3+$} & 15.1 & Shopkeeper, artisan & 2.7 & & \\
\hline & & Street seller & 15.9 & & \\
\hline \multicolumn{2}{|l|}{ Sex of the head of household } & No occupation & 66.4 & & \\
\hline Male & 78.4 & Pupil & 5.7 & & \\
\hline \multirow[t]{2}{*}{ Female } & 21.6 & & & & \\
\hline & & Education & & & \\
\hline Time in Brazzaville & & No schooling & 15.1 & & \\
\hline $0-4$ years & 4.6 & Primary school & 18.5 & & \\
\hline $5-9$ years & 8.4 & Secondary school & 51.3 & & \\
\hline $10-19$ years & 21.1 & Higher & 15.1 & & \\
\hline $20+$ years & 65.9 & & & & \\
\hline \multicolumn{6}{|l|}{ Time in the present home } \\
\hline $0-4$ years & 28.0 & \multicolumn{4}{|c|}{ Adjustment variables for type I models } \\
\hline $5-9$ years & 19.6 & & & & \\
\hline \multirow[t]{2}{*}{$10+$ years } & 52.4 & Age & & Sex & \\
\hline & & $<20$ years & 10.1 & Male & 50.1 \\
\hline Lodging status & & $20-29$ years & 56.2 & Female & 49.9 \\
\hline House owner & 35.5 & $30+$ years & 33.7 & & \\
\hline Lease holder & 39.2 & & & Age & \\
\hline \multirow[t]{2}{*}{ Free lodging } & 25.3 & & & $0-11$ months & 20.0 \\
\hline & & & & $12-23$ months & 17.8 \\
\hline \multicolumn{2}{|l|}{ Economic level } & & & $24-72$ months & 62.2 \\
\hline Low & 30.4 & & & & \\
\hline Medium & 34.2 & & & & \\
\hline \multirow[t]{2}{*}{ High } & 35.4 & & & & \\
\hline & & \multicolumn{4}{|c|}{ Additional adjustment variables for type II model } \\
\hline \multicolumn{2}{|l|}{ Occupation of the head of household } & & & & \\
\hline Middle management & 25.1 & Height & & Birth weight & \\
\hline Worker & 19.4 & Mean $=1.60 \mathrm{~m}(\mathrm{SD}=0.06)$ & & Mean $=3053 \mathrm{~g}(\mathrm{SD}=525)$ & \\
\hline Office worker & 12.9 & & & & \\
\hline Shopkeeper, artisan & 13.5 & BMI & & & \\
\hline No occupation & 29.0 & Mean $=23.1 \mathrm{~kg} \mathrm{~m}^{-2}(\mathrm{SD}=4.3$ & & & \\
\hline \multicolumn{6}{|l|}{ Education of the head of household } \\
\hline No schooling & 14.3 & & & & \\
\hline Primary school & 21.8 & & & & \\
\hline Secondary school & 29.7 & & & & \\
\hline Higher & 34.2 & & & & \\
\hline
\end{tabular}

The child's birth weight $(P<0.0001)$ and the mother's height $(P<0.0001)$ are significantly linked to the heightfor-age index and stunting, reflecting the strong influence of maternal and prenatal status. Taking these variables into account does not alter the conclusions about the estimated effects of the economic level of the household, of the schooling of the mother and of the dwelling district on the mean height-for-age index (Table 4, model II). However, while adjusting for maternal and prenatal status, the effects of the socioeconomic factors and dwelling district on stunting are modified (Table 5, model II). The effect of the dwelling district remains significant, whereas that of economic level of the household is not any more and the mother's education significance is greatly reduced. This suggests that at least part of the effect of these two variables on the height of children is explained by the prenatal or maternal influence.

The linear model for the mother's BMI and the logistic regression models for thinness and overweight are shown in Table 6. All these models are adjusted for age. The mean 
Table 2 General linear model: weight-for-height index in children aged $<6$ years $(n=1163)$

\begin{tabular}{lcc}
\hline $\begin{array}{l}\text { Socioeconomic variables } \\
\text { with significant effect }\end{array}$ & $\begin{array}{c}\text { Model I* } \\
\text { adjusted means }\end{array}$ & $\begin{array}{c}\text { Model II } \dagger \\
\text { adjusted means }\end{array}$ \\
\hline $\begin{array}{l}\text { Number of preschool children in the household } \\
1\end{array}$ & $-0.21^{\mathrm{a}}$ & $-0.17^{\mathrm{a}}$ \\
2 & $-0.45^{\mathrm{b}}$ & $-0.39^{\mathrm{b}}$ \\
& $-0.43^{\mathrm{b}}$ & $-0.37^{\mathrm{b}}$ \\
& $(P=0.007)$ & $(P=0.015)$ \\
\hline Adjustment variables & $P$ value & $P$ value \\
\hline Child's sex & 0.20 & 0.04 \\
Child's age & $2.10^{-7}$ & $2.10^{-8}$ \\
Mother's age & 0.16 & $1.10^{-10}$ \\
Birth weight & - & 0.96 \\
Mother's height & - & $8.10^{-5}$ \\
Mother's BMl & - & \\
*Adjusted for the child's sex and age and the mother's age. & \\
$\begin{array}{l}\dagger \text { Adjusted for the child's sex, age, birth weight and the mother's age, height and BMI. } \\
\text { a,b Means with no common letter are significantly different at the } 0.05 \text { level. }\end{array}$
\end{tabular}

BMI increases with the economic level of the household and when the mother is married, and varies with her occupation. The highest index is observed among salaried mothers and the lowest among housewives and young mothers attending school.

The prevalence of thinness in mothers is less when the head of the household has a higher schooling level but only secondary education significantly increases the odds ratio. No other socioeconomic variable provides further information about weight deficiency in mothers.

The risk of being overweight is smaller among mothers from low economic level households and when they are not married. Compared to the salaried mothers, the risk of being overweight is smaller among all other categories of occupation (except for rare shopkeepers or artisans). The occupation of the head of the household also appears to be linked to levels of overweight in mothers but office workers are the only group for whom the risk seems to be higher.

\section{Discussion}

In spite of the worsening nutritional situation in Brazzaville during the economic $\mathrm{crisis}^{4}$, the rate of malnutrition remained mild among preschool children. Also, as is typical of the nutritional transition phenomenon (which is common in rapidly urbanizing communities), a rather high proportion of mothers featured excess weight

Table 3 Logistic regression models for low weight-for-height index $(<-1$ z-score) in children aged $<6$ years $(n=1163)$

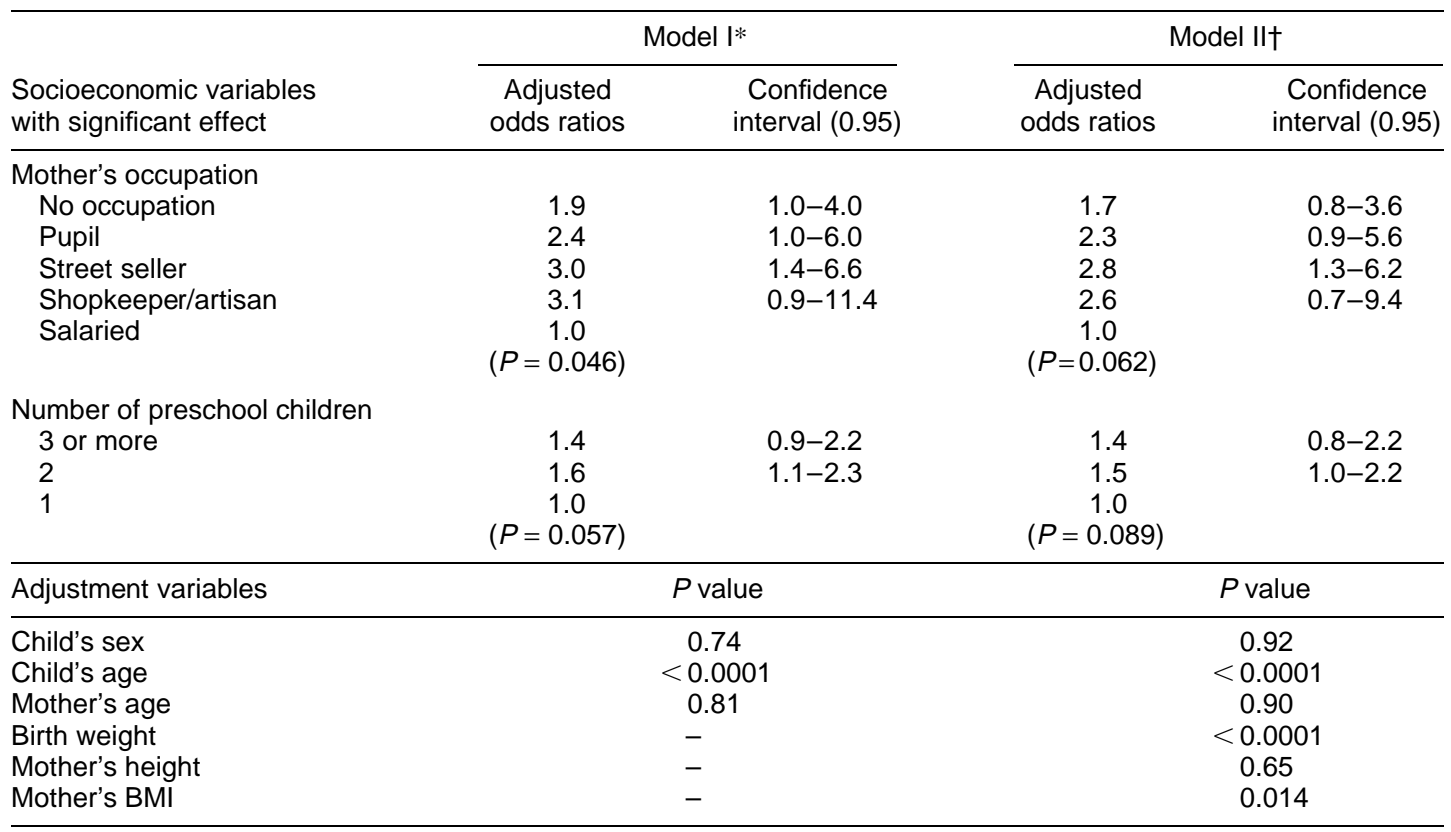

*Adjusted for the child's sex and age and the mother's age.

†Adjusted for the child's sex, age, birth weight and the mother's age, height and BMI. 
Table 4 General linear model: height-for-age index in children aged $<6$ years ( $n=$ 1163)

\begin{tabular}{|c|c|c|}
\hline $\begin{array}{l}\text { Socioeconomic variables } \\
\text { with significant effect }\end{array}$ & $\begin{array}{c}\text { Model I* } \\
\text { adjusted means }\end{array}$ & $\begin{array}{c}\text { Model II† } \\
\text { adjusted means }\end{array}$ \\
\hline $\begin{array}{l}\text { Dwelling district } \\
\text { Peripheral } \\
\text { Intermediate } \\
\text { Central }\end{array}$ & $\begin{array}{c}-0.88^{\mathrm{a}} \\
-0.70^{\mathrm{b}} \\
-0.40^{\mathrm{c}} \\
(P=0.0006)\end{array}$ & $\begin{array}{c}-0.79^{\mathrm{a}} \\
-0.64^{\mathrm{b}} \\
-0.48^{\mathrm{b}} \\
(P=0.030)\end{array}$ \\
\hline $\begin{array}{l}\text { Economic level of the hol } \\
\text { Low } \\
\text { Medium } \\
\text { High }\end{array}$ & $\begin{array}{r}-0.85^{\mathrm{a}} \\
-0.63^{\mathrm{b}} \\
-0.50^{\mathrm{b}} \\
(P=0.004)\end{array}$ & $\begin{array}{r}-0.80^{\mathrm{a}} \\
-0.57^{\mathrm{b}} \\
-0.53^{\mathrm{b}} \\
(P=0.017)\end{array}$ \\
\hline $\begin{array}{l}\text { Mother's education } \\
\text { No schooling } \\
\text { Primary school } \\
\text { Secondary school } \\
\text { Higher }\end{array}$ & $\begin{array}{c}-0.92^{\mathrm{a}} \\
-0.91^{\mathrm{a}} \\
-0.59^{\mathrm{b}} \\
-0.22^{\mathrm{c}} \\
(P=0.00001)\end{array}$ & $\begin{array}{c}-0.78^{\mathrm{a}} \\
-0.86^{\mathrm{a}} \\
-0.57^{\mathrm{b}} \\
-0.33^{\mathrm{c}} \\
(P=0.002)\end{array}$ \\
\hline Adjustment variables & $P$ value & $P$ value \\
\hline $\begin{array}{l}\text { Child's sex } \\
\text { Child's age } \\
\text { Mother's age } \\
\text { Birth weight } \\
\text { Mother's height } \\
\text { Mother's BMl }\end{array}$ & $\begin{array}{l}0.11 \\
2.10^{-7} \\
0.035 \\
- \\
- \\
-\end{array}$ & $\begin{array}{l}0.016 \\
9.10^{-10} \\
0.13 \\
2.10^{-2} \\
3.10^{-16} \\
0.006\end{array}$ \\
\hline
\end{tabular}

Table 5 Logistic regression models for stunting (height-for-age index $<-2$ z-score) in children aged $<6$ years $(n=1163)$

\begin{tabular}{|c|c|c|c|c|}
\hline \multirow[b]{2}{*}{$\begin{array}{l}\text { Socioeconomic variables } \\
\text { with significant effect }\end{array}$} & \multicolumn{2}{|c|}{ Model I* } & \multicolumn{2}{|c|}{ Model IIT } \\
\hline & $\begin{array}{l}\text { Adjusted } \\
\text { odds ratios }\end{array}$ & $\begin{array}{l}\text { Confidence } \\
\text { interval }(0.95)\end{array}$ & $\begin{array}{l}\text { Adjusted } \\
\text { odds ratios }\end{array}$ & $\begin{array}{c}\text { Confidence } \\
\text { interval }(0.95)\end{array}$ \\
\hline \multicolumn{5}{|l|}{ Dwelling district } \\
\hline Peripheral & 3.8 & $1.8-7.8$ & 3.0 & $1.4-6.4$ \\
\hline Intermediate & 2.1 & $1.1-4.2$ & 1.6 & $0.8-3.3$ \\
\hline Central & $\begin{array}{c}1.0 \\
(P=0.0005)\end{array}$ & & $\begin{array}{c}1.0 \\
(P=0.005)\end{array}$ & \\
\hline \multicolumn{5}{|c|}{ Economic level of the household } \\
\hline Low & 2.0 & $1.1-3.6$ & 1.9 & $1.0-3.5$ \\
\hline Medium & 1.7 & $1.0-2.9$ & 1.5 & $0.8-2.6$ \\
\hline High & $\left(P=\begin{array}{l}1.0 \\
0.048)\end{array}\right.$ & & $\left(P=\begin{array}{l}1.0 \\
011)\end{array}\right.$ & \\
\hline \multicolumn{5}{|l|}{ Mother's education } \\
\hline No schooling & 2.9 & $1.2-7.2$ & 2.1 & $0.8-5.3$ \\
\hline Primary school & 2.9 & $1.3-6.7$ & 2.6 & $1.1-6.1$ \\
\hline Secondary school & 1.4 & $0.6-2.9$ & 1.3 & $0.6-2.8$ \\
\hline Higher & 1.0 & & 1.0 & \\
\hline & $(P=0.004)$ & & $(P=0.047)$ & \\
\hline Adjustment variables & \multicolumn{2}{|c|}{$P$ value } & \multicolumn{2}{|c|}{$P$ value } \\
\hline Child's sex & \multicolumn{2}{|c|}{0.0053} & \multicolumn{2}{|c|}{0.0009} \\
\hline Child's age & \multicolumn{2}{|c|}{0.0042} & \multicolumn{2}{|c|}{0.0015} \\
\hline Mother's age & \multirow{2}{*}{\multicolumn{2}{|c|}{0.098}} & \multicolumn{2}{|c|}{$\begin{aligned} & 0.27 \\
< & 0.0001\end{aligned}$} \\
\hline Birth weight & & & \multicolumn{2}{|c|}{$<0.0001$} \\
\hline Mother's height & \multicolumn{2}{|l|}{-} & & \\
\hline Mother's BMI & \multicolumn{2}{|l|}{ - } & \multicolumn{2}{|c|}{0.09} \\
\hline
\end{tabular}

*Adjusted for the child's sex and age and the mother's age.

†Adjusted for the child's sex, age, birth weight and the mother's age, height and BMI. 
Table 6 BMI in mothers: general linear model for continuous BMI and logistic regression models for thinness $\left(\mathrm{BMI}<18.5 \mathrm{~kg} \mathrm{~m}^{-2}\right) \mathrm{vs}$ others and overweight $\left(\mathrm{BMI} \geqslant 25 \mathrm{~kg} \mathrm{~m}^{-2}\right)$ vs others

\begin{tabular}{|c|c|c|c|c|c|}
\hline \multirow[b]{2}{*}{$\begin{array}{l}\text { Socioeconomic variables } \\
\text { with significant effect }\end{array}$} & \multirow[b]{2}{*}{$\begin{array}{c}\text { BMI } \\
\text { adjusted means }\end{array}$} & \multicolumn{2}{|c|}{ Underweight } & \multicolumn{2}{|c|}{ Overweight } \\
\hline & & $\begin{array}{l}\text { Adjusted } \\
\text { odds ratios }\end{array}$ & $\begin{array}{l}\text { Confidence } \\
\text { interval (0.95) }\end{array}$ & $\begin{array}{l}\text { Adjusted } \\
\text { odds ratios }\end{array}$ & $\begin{array}{l}\text { Confidence } \\
\text { interval (0.95) }\end{array}$ \\
\hline \multicolumn{6}{|l|}{ Economic level of the household } \\
\hline Low & $21.4^{\mathrm{a}}$ & 2.1 & $1.1-4.1$ & 0.3 & $0.2-0.5$ \\
\hline Medium & $22.5^{\mathrm{b}}$ & 1.7 & $0.9-3.1$ & 0.8 & $0.5-1.2$ \\
\hline High & $\begin{array}{c}23.2^{\mathrm{C}} \\
\left(P=3.10^{-5}\right)\end{array}$ & $(P=0.06)$ & & $\begin{array}{c}1.0 \\
(P<0.0001)\end{array}$ & \\
\hline \multicolumn{6}{|l|}{ Mother's occupation } \\
\hline No occupation & $21.7^{\mathrm{a}}$ & & & 0.2 & $0.1-0.5$ \\
\hline Pupil & $21.3^{\mathrm{a}}$ & & & 0.2 & $0.1-0.5$ \\
\hline Street seller & $22.0^{\mathrm{a}}$ & & & 0.3 & $0.1-0.9$ \\
\hline Shopkeeper/artisan & $22.5^{\mathrm{ab}}$ & & & 0.7 & $0.1-2.9$ \\
\hline Salaried & $24.4^{\mathrm{b}}$ & & & 1.0 & \\
\hline & $(P=0.0009)$ & & & $(P=0.001)$ & \\
\hline \multicolumn{6}{|l|}{ Marital status of the mother } \\
\hline Single & 21.6 & & & 0.2 & $0.1-0.5$ \\
\hline Married & 23.1 & & & 1.0 & \\
\hline & $(P=0.01)$ & & & $(P=0.0002)$ & \\
\hline \multicolumn{6}{|c|}{ Education of the head of household } \\
\hline No schooling & & 1.1 & $0.4-2.8$ & & \\
\hline Primary school & & 1.0 & $0.5-2.3$ & & \\
\hline Secondary school & & 2.6 & $1.4-4.9$ & & \\
\hline Higher & & 1.0 & & & \\
\hline & & $(P=0.006)$ & & & \\
\hline \multicolumn{6}{|c|}{ Occupation of the head of household } \\
\hline No occupation & & & & 1.0 & $0.5-1.7$ \\
\hline Shopkeeper/artisan & & & & 1.0 & $0.5-2.0$ \\
\hline Office worker & & & & 2.2 & $1.2-4.0$ \\
\hline Worker & & & & 0.6 & $0.3-1.1$ \\
\hline \multirow[t]{2}{*}{ Middle management } & & & & 1.0 & \\
\hline & & & & $(P=0.007)$ & \\
\hline Effect of the age of the mother & $P=4.10^{-5}$ & \multicolumn{2}{|c|}{$P=0.003$} & \multicolumn{2}{|c|}{$P=0.007$} \\
\hline
\end{tabular}

a,b,c Means with no common letter are significantly different at the 0.05 level.

or marked obesity ${ }^{12}$. Thus, even if the prevalence of thinness among mothers increased - and it is likely that the prevalence of overweight has also been limited by the crisis - the overall nutritional situation in Brazzaville was not so dire. This was probably due to the specificity of this urban area where, even though poverty increased, food supplies, access to safe water, electricity and to other facilities such as health care are usually better than in rural areas. Nevertheless, it is likely that the effects of the crisis were not distributed evenly in the population of Brazzaville. It was then important to determine which socioeconomic or dwelling district features were linked to the different types of malnutrition after several years of crisis. It was also of interest to assess whether the conceptual model of underlying causes of malnutrition adopted by the International Conference on Nutrition $(\mathrm{ICN})^{13}$ is still valid in this context, and how the effects of the economic crisis were mediated by socioeconomic and prenatal factors.

Three factors have independent effects (i.e. adjusted for each other and for all the other variables) on the mean height-for-age index of children and on stunting: children from households with a low economic level, children whose mothers have had only little schooling and children who live in the peripheral area are more at risk of stunting than others. As for the assessment of economic level of the household, it is important to notice that the variables used in computing the economic index reflect more the permanent living conditions of the households than current cash availability; a low economic level thus indicates medium to long-term poverty ${ }^{9}$. Although a low level of education is generally associated with poverty, the effect of the education of the mother on the height of children remains when adjusted for the economic level. This underlines a differential ability of the mothers to take care of their young children, according to their level of education, independently of the economic level of the household. Indeed, the results suggest the importance of a minimum level of education for mothers to adequately care for their children and thus ensure satisfactory growth $^{14}$. The dwelling district variable takes into account access to health services, general infrastructure, hygiene and sewage facilities which are strongly contrasted between the three districts. The fact that, even when adjusted for economic level of the household, stunting is linked to this variable, whereas the BMI of the mothers is 
not, confirms the hypothesis that the nutritional status of children is much more sensitive to environmental conditions than that of adults ${ }^{15}$.

When the three preceding characteristics are accounted for, none of the other variables actually provides further significant information on stunting. So, this combination of economic level of the household, mother's schooling and dwelling district seems to summarize most of the influence of the socioeconomic and environmental context on the growth of the children in our study. These three factors are closely related to the three categories of underlying causes of malnutrition in the ICN conceptual model: household food security, maternal and child care, health services and general environment. It could then be assumed that even in a crisis context these three types of causes are still the main determinants of child growth.

Our results show that, as expected ${ }^{16}$, the physical maternal and child prenatal characteristics are strongly related to children's nutritional indices, especially stunting. When adjusting for these characteristics, the mean height-for-age index remains linked to dwelling environment, mother's schooling and economic level of the household. But the link with stunting is somewhat reduced, especially for the latter. These results suggest that a great part of the effect of economic level is probably accounted for by maternal and prenatal status. In contrast, the dwelling district seems to act more directly on the children as the link with stunting is much less reduced by the adjustment. As far as stunting is concerned, these results hint that, independently of all other characteristics, a degradation or an improvement of the dwelling environment conditions is likely to have a direct effect on the growth of young children. The strong link with physical maternal characteristics (especially height) may suggest that a degradation or an improvement of the economic level of the households (as taken into account by our economic index), is likely to modify stunting prevalence in the mid to long term. This is linked to the concept of the intergeneration effect of poverty ${ }^{17}$. Nevertheless, other maternal factors that may more directly alter prenatal characteristics also have to be taken into account, such as short-term effects of the economic crisis on the mother's diet and energy expenditure.

Wasting in children is influenced by the mother's occupation: a salaried mother is a significant protective factor. However, an influence of the economic level of the household was not shown. This is consistent with the fact that wasting is a much more short-lived phenomenon than stunting; it may appear very rapidly and disappear just as fast $^{6}$. Indeed, if the economic index refers to a medium- to long-term situation, salaried status implies the existence of a current income controlled by the mother and hence more likely to be devoted to her own needs and/or to the nutrition and health of her young children ${ }^{18}$. Adjusted for all other variables, the number of preschool children also has an effect on the weight-for-height index, which is higher when there is only one child aged $<6$ years in the household. In the latter situation, it is likely that the mother has more time available for providing adequate caring to her child. But the feature that stands out is that few socioeconomic variables are shown to affect the weightfor-height index or wasting of the children ${ }^{19}$. Children aged 12-23 months remain the most at risk when all socioeconomic, maternal and prenatal characteristics have been taken into account. Whatever the economic level of the household, the level of education or profession of the mother and/or the head of household, this weaning period is especially critical.

The mother's BMI is strongly related to the economic level of the household as previously shown in a broader setting ${ }^{20}$. Even after adjustment for age, the prevalence of being overweight peaks in those from high economic level households. Adjusted for all the other variables, and especially economic level of the household, the salaried mothers, the married ones and those from households headed by office workers (as opposed to executives and all others professions) feature a higher mean BMI and prevalence of being overweight. These results indicate the influence of an own income of the mother and of some specific sociocultural determinants, such as a more stable situation, on BMI and overweight levels. On the other hand, mothers from low economic level households and the non-salaried ones show a lower mean BMI. In a crisis period some women are the first to suffer the consequences of a reduction in household food supplies, as one of the secondary effects of the reduction in available food is often increased physical activity ${ }^{21}$. Indeed, a lot of mothers must, more than ever, participate in the family strategies developed to ensure a minimal income. This has a negative effect on their nutritional status and hence on the prenatal factors of their children's growth. On the other hand, spending more time on economic activities (frequently informal), the mothers have less time to look after their children at home and to attend preventive sessions organized by the health services. This was shown to have a significant impact on the stunting of children in another study in Brazzaville ${ }^{22}$.

Thus, our results suggest that in this African urban context the conceptual model of underlying causes of malnutrition ${ }^{13}$ is still relevant, especially for stunting, even after several years of crisis. But our study also emphasizes that various mechanisms are involved to explain the nutritional situation of children. Some of the determinants studied, mainly the characteristics of the dwelling environment, seem to act directly on the children. Other factors, in particular the economic level of the household, are mediated through the nutritional status of the mother.

\section{Acknowledgements}

L. Bérard and P. Villeneuve took part in the survey which was supported by ORSTOM and UNICEF Brazzaville. 


\section{References}

1 Thomas D, Lavy V, Strauss J. Public Policy Anthropometric Outcomes in Côte d'Ivoire. Living Standards Measurement Study. Working Paper No. 89. Washington DC: The World Bank, 1992.

2 République du Congo, UNICEF. Analyse de la Situation des Enfants et des Femmes au Congo. Brazzaville: Bureau UNICEF, 1992.

3 Simondon F, Delpeuch F, Cornu A, et al. Etat nutritionnel des enfants d'âge préscolaire à Brazzaville. In: Salem G, Jeannée E, eds. Urbanisation et Santé dans le Tiers Monde. Transition Épidémiologique, Changement Social et Soins de Santé Primaires. Paris: ORSTOM, Collection Colloques et Séminaires, 1989; 115-27.

4 Cornu A, Massamba JP, Traissac P, Simondon F, Villeneuve P, Delpeuch F. Nutritional change and economic crisis in an urban Congolese community. Int. J. Epidemiol. 1995; 24: 155-64.

5 République du Congo. Recensement Général de la Population et de l'Habitat, Vol. 1, Résultats Provisoires. Brazzaville: Ministère du Plan, Bureau Central du Recensement, 1985.

6 WHO. Physical Status: The Use and Interpretation of Anthropometry. WHO Technical Report Series No. 854. Geneva: World Health Organization, 1995.

7 Dean AD, Dean JA, Burton JH, Dicker RC. Epi Info, Version 5: A Word Processing, Database, and Statistics Program for Epidemiology on Micro-computers. Atlanta, Georgia: Centers for Disease Control, 1990.

8 SAS Institute Inc. SAS/STAT User's Guide, Version 6, 4th edn. Vols 1 and 2. Cary, NC: SAS Institute Inc., 1989.

9 Traissac P, Delpeuch F, Maire B, Martin-Prével Y, Cornu A, Trèche $\mathrm{S}$. Construction d'un indice synthétique de niveau économique des ménages dans les enquêtes nutritionnelles. Exemples d'application au Congo. Rev. Epidemiol. Sante Publique 1997; 45 (Suppl. 1): 114-15.

10 Searle SR. Linear Models for Unbalanced Data. New York: John Wiley, 1987.

11 Hosmer DW, Lemeshow S. Applied Logistic Regression. New York: John Wiley, 1989.

12 Maire B, Delpeuch F, Cornu A, et al. Urbanisation et transition nutritionnelle en Afrique Sub-Saharienne: les exemples du Congo et du Sénégal. Rev. Epidemiol. Sante Publique 1992; 40: 252-8.

13 FAO/WHO. Nutrition and Development - A Global Assessment. International Conference on Nutrition. Rome: Food and Agriculture Organization/World Health Organization, 1992.

14 Ruel MT, Habicht JP, Pinstrup-Andersen P, Gröhn Y. The mediating effect of maternal nutrition knowledge on the association between maternal schooling and child nutritional status in Lesotho. Am. J. Epidemiol. 1992; 135: 90414.

15 Shetty PS, James WPT. Body Mass Index: A Measure of Chronic Energy Deficiency in Adults. FAO Food and Nutrition Paper No. 56. Rome: Food and Agriculture Organization, 1994.

16 Kramer MS. Determinants of low birth weight: methodological assessment and meta-analysis. Bull. World Health Organ. 1987; 65: 663-737.

17 Sanderson M, Emanuel I, Holt VL. The intergenerational relationship between mother's birth weight, infant birth weight and infant mortality in black and white mothers. Paediatr. Perinat. Epidemiol. 1995; 9: 391-405.

18 Kennedy E, Haddad L. Food security and nutrition, 1971-91. Lessons learned and future priorities. SCN News 1992; 8: 8-9.

19 Frongillo EA Jr, de Onis M, Hanson KM. Socio-economic and demographic factors are associated with worldwide patterns of stunting and wasting of children. J. Nutr. 1997; 127: 23029.

20 Delpeuch F, Cornu A, Massamba JP, Traissac P, Maire B. Is body mass index (BMI) sensitively related to socioeconomic status and to economic adjustment? A case study from Congo. Eur. J. Clin. Nutr. 1994; 48 (Suppl. 3): S141-7.

21 Garcia M. Women's food intake and nutritional status in Pakistan and the Philippines: effects of incomes and prices. In: Wahlqvist et al. Nutrition in a sustainable environment. Proceedings of the XVth International Congress of Nutrition. London: Smith-Gordon, 1994; 167-70.

22 Martin-Prével Y, Coudert K, Traissac P, et al. Évolution de la situation nutritionnelle des jeunes enfants à Brazzaville (Congo), après la dévaluation du franc cfa. Rev. Epidemiol. Sante Publique 1997; 45 (Suppl. 1): 110-11. 